\title{
Effect of a pharmacist managed smoking cessation clinic on quit rates
}

Ann M. PHILBRICK, Erin N. NEWKIRK, Karen B. FARRIS, Deanna L. McDANEL, Kathleen E. HORNER.

\begin{abstract}
${ }^{*}$
Objective: The purpose of this study was to quantify quit rates, determine factors predicting success, and analyze patients' perceptions at 3 months after participation in the pharmacist-managed Smoking Cessation Group Clinic.

Methods: This was a prospective, single group study that was conducted in patients that had participated in the Smoking Cessation Group Clinic at the University of lowa Hospitals and Clinics. Clinic participants received structured group counseling covering various topics associated with cessation. Varenicline, bupropion and nicotine replacement therapy were used as smoking cessation aids and selection was based on patient preference and absence of contraindications. The primary outcome of this trial was smoking status at 3 months. The patients were contacted by telephone at 3, and 6 months after the start of the clinic and asked about current smoking status. At 3 months, patients were asked to rate on a Likert scale of 1 to 5 ( $1=$ not helpful; $5=$ very helpful) their perceptions of individual aspects of the clinic and on a scale of 1 to 10 ( $1=$ not helpful; $10=$ very helpful) how they perceived their cessation aid.

Results: From February 2007 to January 2008, 21 patients enrolled in the intent-to-treat follow up study. Analysis of data was completed in August 2008. At 3 and 6 months, $47.6 \%$ and $52.4 \%$, of patients reported being smoke-free, respectively. At 3 months, factors consistent with success included having more previous quit attempts and type of cessation aid used. These endpoints continued to be significant at 6 months, in addition to attending more clinic sessions, and type of insurance (favoring private insurance). Patients who quit smoking rated their cessation aid as more helpful than those who did not quit smoking (8.56; $S D=0.88$ verses $6.71 ; S D=2.81$, respectively; $p=0.14)$. The
\end{abstract}

\footnotetext{
Ann M. PHILBRICK. Pharm.D. Assistant Professor. Department of Pharmaceutical Care and Health Systems, College of Pharmacy. University of Minnesota. Minneapolis, MN (United States).

Erin N. NEWKIRK. Pharm.D. Clinical Pharmacist.

Department of Pharmacy, Froedtert Hospital. Milwaukee, WI (United States).

Karen B. FARRIS. B.S, Ph.D. Professor. University of lowa College of Pharmacy. The University of lowa. lowa City, IA (United States).

Deanna L. McDANEL. Pharm.D. Clinical Pharmacy Specialist. University of lowa Hospitals and Clinics, lowa City, IA. Assistant Professor (Clinical). University of lowa College of Pharmacy, lowa City, IA (United States). Kathleen E. HORNER. Pharm.D. Clinical Pharmacy Specialist. University of lowa Hospitals and Clinics, lowa City, IA. Assistant Professor (Clinical). University of lowa College of Pharmacy, lowa City, IA (United States).
}

aspect of the clinic most helpful to patients was group interaction (4.53; $\mathrm{SD}=0.77$ ).

Conclusion: This study demonstrates that pharmacists can play a vital role with smoking cessation in a group setting. Group setting patient counseling can be an effective tool for pharmacists to reach more people within the same time frame as individual counseling.

Keywords: Smoking Cessation. Health Education. Pharmacists. United States.

\section{EFECTO DE LAS CLÍNICAS DE CESACIÓN TABÁQUICA GESTIONADAS POR UN FARMACÉUTICO EN LA TASA DE ABANDONO}

\section{RESUMEN}

Objetivo: El propósito de este estudio fue cuantificar las tasas de abandono, los factores determinantes que predicen el éxito y analizar las percepciones de los pacientes después de 3 meses de participar en un grupo de una clínica de cesación tabáquica gestionada por un farmacéutico.

Métodos: Este fue un estudio prospectivo de grupo único que se realizó en pacientes que habían participado en el Smoking Cessation Group Clinic de los Hospitales y Clínicas de la Universidad de Iowa. Los participantes en la clínica recibieron consejo estructurado en grupo que cubrió varios puntos relacionados con la cesación. Se utilizaron vareniclina, bupropion y tratamiento sustitutivo de nicotina como ayudas a la cesación y la selección se basaba en las preferencias del paciente y en la ausencia de contraindicaciones. El resultado primario de este estudio era el dejar de fumar a los tres meses. Se contactó a los pacientes por teléfono a los 3 y 6 meses de empezar en la clínica y se les preguntó sobre su estado actual de fumador. A los 3 meses, se pidió a los pacientes que valoraran en una escala Likert de 1 a 5 (1=sin ayuda; 5=de mucha ayuda) sus percepciones de los aspectos individuales de la clínica, y en una escala de 1 a 10 ( $1=$ sin ayuda; $10=$ de mucha ayuda) como percibieron las ayudas a la cesación.

Resultados: De febrero 2007 a enero 2008, 21 pacientes se enrolaron en el estudio de seguimiento de intención-de-tratar. El análisis de los datos se completó en agosto de 2008. A los 3 y 6 meses, el $47,6 \%$ y $52,4 \%$ de los pacientes, respectivamente, comunicaron estar libres del tabaco. A los 3 meses, los factores consistentes con el éxito incluían haber realizado otros intentos previos de abandono, y el tipo de ayuda de cesación utilizada. Estos puntos finales continuaron significativos a los 6 meses, 
además de asistir a más sesiones de la clínica, y el tipo de seguro médico (a favor de los seguros privados). Los pacientes que dejaron de fumar valoraron sus ayudas de cesación como más útiles que los que no dejaron de fumar $(8,56 ; \mathrm{DE}=0,88$ contra 6,$71 ; \mathrm{DE}=2,81$, respectivamente; $\mathrm{p}=0.14)$. El aspecto de la clínica más útil para los pacientes fue la interacción en grupo $(4,53 ; \mathrm{DE}=0,77)$.

Conclusión: Este estudio demuestra que los farmacéuticos pueden jugar un papel vital en la cesación tabáquica en un ambiente de grupo. Aconsejar en grupo a los pacientes puede ser una herramienta efectiva para que los farmacéuticos lleguen a más gente al mismo tiempo que con el consejo individual.

Palabras clave: Cesación tabáquica. Educación sanitaria. Farmacéuticos. Estados Unidos.

\section{INTRODUCTION}

Cigarette smoking is the leading cause of preventable death in the United States, attributing to approximately 440,000 deaths per year. ${ }^{1}$ It has been linked to numerous disease states, most prominently lung cancer, and has been shown to account for $87 \%$ of all lung cancer deaths. ${ }^{2}$ The United States Department of Health and Human Services Healthy People 2010 objective for smoking cessation is to decrease the prevalence of smoking to less than $12 \%$ of all Americans by 2010 . $^{3}$ The occurrence of smoking will need to be dramatically decreased, as the Centers for Disease Control and Prevention estimated the prevalence of cigarette smoking among adult Americans to be $19.8 \%$ in $2007^{4}$ This has decreased only slightly from $22.5 \%$ in 2002. ${ }^{5}$ In order to achieve these goals more emphasis needs to be placed on increasing the availability of smoking cessation programs. Pharmacists are a ready-available smoking cessation resource with the tools and capacity to help achieve the Health People 2010 goal.

In July 2006, the University of lowa Hospitals and Clinics implemented a campus-wide smoking ban. The purpose of this smoking ban was to comply with the goal of the lowa Hospital Association and lowa Attorney General's Office to make all hospitals in lowa smoke-free environments. In addition, it had the potential to have positive effects on increasing smoking cessation rates. A systematic review of 26 studies investigating the effects of smoking bans in the workplace found that smoking bans led to a $3.8 \%$ reduction in the prevalence of smokers among employees. Furthermore, those employees that continued smoking averaged 3.1 fewer cigarettes per day. ${ }^{6}$ The initiation of the ban at University of lowa Hospitals and Clinics opened the door for development of additional smoking cessation programs in order to help patients, caregivers, and employees in need of smoking cessation therapy.

The United States Public Health Guidelines for Treating Tobacco Dependence recommend a combination of tobacco cessation counseling and pharmacotherapy be provided in order to maximize effectiveness of cessation efforts. ${ }^{7}$ Several published studies document the results of one on one pharmacist managed smoking cessation clinics, while few published studies describe group counseling sessions. The first study describes a group smoking cessation clinic designed to mimic the transtheoretical model of change at a Veterans Affairs Medical Center. ${ }^{8}$ The transtheoretical model of change is designed to promote change through five stages: precontemplation, contemplation, preparation, action, and maintenance. ${ }^{9}$ Patients attended three group sessions, each lasting approximately one hour. A follow-up telephone survey was conducted of the participants in this program and 130 of the 148 participants completed the survey. Of the participants contacted, 54 $(41.5 \%)$ had continued cessation. These patients were at various stages beyond the end of their group clinic, ranging from six months to three years. ${ }^{8}$ Another group-based clinic was studied by Zillich and colleagues and consisted of twelve, weekly, one hour group sessions. Thirty-one patients were enrolled in the study. Smoking abstinence was chemically verified with a carbon monoxide monitor. Cessation rates for three and six months were thirteen patients (42\%) and eight patients $(26 \%)$ respectively. ${ }^{10}$ Finally, the most promising study was a prospective, randomized controlled trial. Participants were randomly assigned to receive a 3-session face to face group program with a clinical pharmacist or a telephone counseling session lasting 5 to 10 minutes. Patients could use bupropion or nicotine replacement products and cessation was confirmed using urinary cotinine. At the end of 6 months, cessation rates were $28 \%$ in those receiving the group counseling cessations and $11.8 \%$ in the telephone counseling $(p<0.041){ }^{11}$ The study presented here adds to the smoking cessation literature in that it further supports the role of a pharmacist in a group smoking cessation counseling setting and identifies characteristics associated with success.

\section{METHODS}

Development and Design. The pharmacistmanaged Smoking Cessation Group Clinic at University of lowa Hospitals and Clinics was established between August 2006 and February 2007. During the planning stages for the clinic, meetings were conducted with several committees at the hospital. The Department of Pharmaceutical Care provided the clinic with pharmacist staff and supplies. After several meetings with Information Technology and the Health Information Management Subcommittee, a consult form on the electronic medical record was developed in order to ease the process of referring patients into the clinic. Finally, the Family Care Center Leadership Team granted the clinic pilot status and provided space to hold the clinic. This status meant the Family Care Center would not gather a fee for the clinic as they wanted to first gauge the effectiveness and the profitability of the clinic before employing clerical staff to bill for the clinic. The design of the clinic was 
formulated from materials available from other pharmacist-managed smoking cessation programs and professional organizations and followed the Transtheoretical Model of Change. ${ }^{9}$ The clinic was administered by at least one clinical pharmacist in a multi-meeting, group session format. This was a prospective, single group study. This study was approved by the University of lowa Institutional Review Board and participants signed informed consent.

Subjects. Participants were eligible for the clinic and follow up survey if they were over the age of 18 years old, smoked at least one cigarette daily, and were willing to quit smoking within the first 30 days of the clinic.

Intervention. Every group was limited to no more than twelve patients. Each clinic met six times over the course of eight weeks, with the first four sessions occurring weekly and the last two occurring biweekly. At least two phone contacts made to each patient within the eight week period. Each session lasted approximately 45 minutes. All clinics met over the noon hour with the exception of one clinic that met in the evening.

Study Medications. Patients were counseled on the risks and benefits of nicotine replacement therapy, bupropion and varenicline at the first clinic session. They were then telephoned by the clinical pharmacist before the second clinic meeting to discuss which therapy would be best suited for them. The clinical pharmacist reviewed the patient's electronic medical record for contraindications or precautions for therapy. If the patient wished to use smoking cessation pharmacotherapy, the clinical pharmacist formulated a recommendation and presented it to the patient's primary care provider for approval. Doses for smoking cessation pharmacotherapy aligned with each product's prescribing information. Prescriptions were provided by the primary care provider.

Baseline Assessment. After a patient was referred to the Smoking Cessation Group Clinic, a clinical pharmacist contacted them by phone. The purpose of this call was to explain the clinic and enroll those meeting inclusion criteria. Also at this time the Fagerstrom Tolerance score was determined and demographics (age, gender, number of previous quit attempts, and current number of cigarettes smoked per day) were collected. The Fagerstrom Tolerance score is an eight item questionnaire based out of eleven points to gage a person's addiction to nicotine. Research has shown that a score of less than 6 or 7 correlates with successful cessation. $^{12}$

Follow-up Measures. Patients that consented to the follow-up study and were contacted by telephone at 3 and 6 months past the starting date of their first group clinic meeting. For continuity of care, the clinical pharmacist that led the group sessions contacted patients. At all endpoints, self-reported smoking cessation status and adverse effects were attained via a telephone questionnaire. Patients were asked "are you currently smoke free" to determine smoking status. At 3 months, patients were asked to rate on a Likert scale of 1 to $5(1=$ not helpful; $5=$ very helpful) their perceptions of individual aspects of the clinic and a scale of 1 to 10 ( $1=$ not helpful; $10=$ very helpful) how they perceived their cessation aid.

Outcomes. The primary outcome of this study was smoking status at 3 months. The first secondary outcome was to determine patient variables that predicted success at 3 and 6 months, including cessation aid used, age, gender, Fagerstrom Tolerance score, number of previous quit attempts, average number of cigarettes smoked daily, setting a quit date and the number of sessions attended. Additional secondary outcomes included patient perceptions of the cessation aid they used and individual aspects of the clinic.

Analysis. Patients were enrolled from February 2007 to January 2008, with the final telephone follow-up occurring in July 2008. Data analysis was completed in August 2008. This study used an intention-to-treat analysis with those patients lost to follow-up being treated as smokers. Descriptive statistics and frequency distributions were calculated. The percent of patients smoke-free at three and six months was tabulated. As well, descriptive statistics were calculated for rating aspects of the smoking cessation clinic. Chi-square or Fisher's Exact 2-sided tests were done to examine the association with being smoke-free at 3 and 6 months for gender, pharmacotherapy used, setting a quit date and number of sessions attended. T-tests were completed on age, Fagerstrom Tolerance Score, number of previous quit attempts and number of cigarettes smoked per day by smoke-free status at 3 and 6 months.

\section{RESULTS}

From February 2007 to January 2008, 73 patients were referred to the Smoking Cessation Group Clinic. Of those referred, 26 (45.6\%) enrolled into the clinic. Referrals were from physicians (primary care and specialty), pharmacists, or by self referral. Over half of the patients that referred themselves to the clinic enrolled in the clinic, however source of referral played no role in cessation success $(p=0.263)$. Five of the 26 participants in the clinic did not consent as they did not want to be called, leaving 21 patients in the intent-to-treat follow up study. The majority of patients were female $(61.9 \%)$. Other baseline characteristics of patients enrolled in the follow-up study are depicted in Table 1.

\begin{tabular}{|l|c|}
\hline \multicolumn{2}{|l|}{ Table 1: Baseline Characteristics of Study } \\
Participants \\
\hline Characteristic $(\mathrm{n}=21)$ & Mean (SD) \\
\hline Age & $49.2(10.3)$ \\
\hline Fagerstrom Score & $5.48(2.4)$ \\
\hline Sessions Attended & $4(1.8)$ \\
\hline Cigarettes per Day & $19.9(11.2)$ \\
\hline
\end{tabular}

Three Month Results. The primary outcome of the study was self-reported patient cessation rates at three months, and 10 people (47.6\%) achieve this outcome. It should be noted that 12 patients quit smoking by the end of their clinic visit, but 2 people resumed smoking within the four week period 
following the end of the clinic before pharmacist follow up. Of the 10 people stating they were smoke free, 5 patients reported having slips during the 3 month follow up period. Of the 11 patients reporting that were not smoke free, 8 patients did not quit during the clinic period. Nine patients reported smoking fewer cigarettes at 3 months than at baseline.

Predictors of Success. One of the secondary outcomes was determining if any patient variables predicted success. At three months, there was a $77.8 \%$ success rate in the group that used nonnicotine prescription medication, $28.6 \%$ in those that used nicotine replacement therapy and $20 \%$ in those that used no pharmacotherapy $(p=0.054$, Table 2). Nine patients used non-nicotine prescription medications, either sustained-release bupropion $(n=3)$ or varenicline $(n=6), 7$ patients used nicotine replacement therapy and 5 patients did not use pharmacotherapy. No patients used a combination of nicotine replacement therapy and non-nicotine

pharmacotherapy,

however combination would have been allowed under physician supervision. Adverse effects reported with varenicline were limited to nausea and abnormal dreams. There were no adverse effects reported with sustained release bupropion or nicotine replacement therapy.

Characteristics of previous quit attempts were examined to determine any association with success in the current quit attempt. The number of previous quit attempts was significantly associated with success at 3 months (Table 3 ). On average the patients who were smoke-free had $6 \mathrm{SD}=5.9$ quit attempts versus $2.64 \mathrm{SD}=2.0$ attempts in those patients who continued to smoke $(p=0.050)$. Additionally, setting a quit date proved to be beneficially in quitting as $70 \%$ of those that set a quit date were successful verses $27.3 \%$ of those that did not set a quit date $(p=0.050$; Figure 1). No other factors affected success at 3 months (Table $3)$.

\begin{tabular}{|c|c|c|c|c|c|c|}
\hline & & Months & & & Months & \\
\hline & Non Smoker & Smoker & P-value & Non Smoker & Smoker & P-value \\
\hline No Medication & $20 \%$ & $80 \%$ & \multirow{3}{*}{0.054} & $20 \%$ & $80 \%$ & \multirow{3}{*}{0.014} \\
\hline Nicotine Replacement Therapy & $28.6 \%$ & $71.4 \%$ & & $28.6 \%$ & $71.4 \%$ & \\
\hline Oral Prescription Aids & $77.8 \%$ & $22.2 \%$ & & $88.9 \%$ & $11.1 \%$ & \\
\hline
\end{tabular}

\begin{tabular}{|l|c|c|c|c|c|c|}
\hline Table 3: Characteristics of Previous Smoking Cessation and Cessation Rates \\
\hline \multirow{2}{*}{ Characteristic } & \multicolumn{3}{|c|}{ 3 months } & \multicolumn{3}{c|}{6 months } \\
\cline { 2 - 7 } & $\begin{array}{c}\text { Non Smoker } \\
\text { mean (SD) }\end{array}$ & $\begin{array}{c}\text { Smoker } \\
\text { mean (SD) }\end{array}$ & P-value & $\begin{array}{c}\text { Non Smoker } \\
\text { mean (SD) }\end{array}$ & $\begin{array}{c}\text { Smoker } \\
\text { mean (SD) }\end{array}$ & P-Value \\
\hline Previous Quit Attempts & $6.00(5.9)$ & $2.64(2.0)$ & 0.050 & $5.91(4.7)$ & $2.4(2.0)$ & 0.040 \\
\hline Age & $51.2(7.8)$ & $47.5(12.2)$ & 0.417 & $51.36(7.7)$ & $46.90(12.5)$ & 0.332 \\
\hline Fagerstrom Score & $4.5(2.2)$ & $6.36(2.3)$ & 0.072 & $4.82(2.3)$ & $6.2(2.3)$ & 0.191 \\
\hline Cigarettes/Day & $18.6(12.6)$ & $21.0(10.2)$ & 0.636 & $21.0(12.5)$ & $18.6(8.6)$ & 0.636 \\
\hline Sessions Attended & $4.8(1.8)$ & $3.27(1.6)$ & 0.52 & $4.82(1.5)$ & $3.1(1.7)$ & 0.026 \\
\hline
\end{tabular}

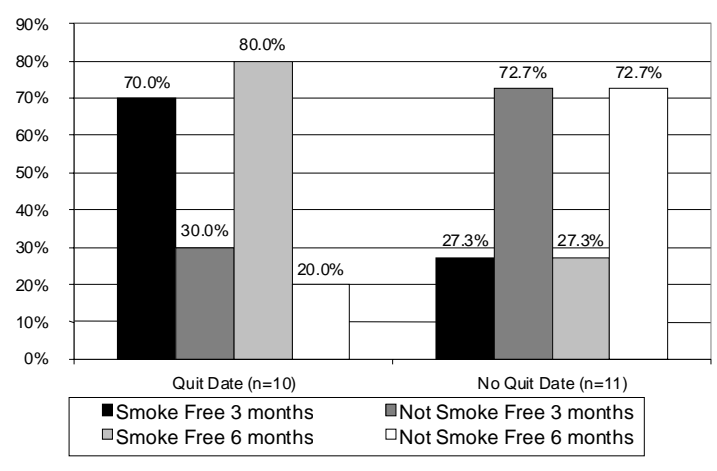

Figure 1: Cessation Rates By Setting a Quit Date

Six Month Results. Although not a primary outcome, success at 6 months was $52.4 \%$ (Table 2). One patient that reported smoking at 3 months reported a smoke free status at 6 months. Those factors that were associated with success at three months also showed success in the six month analysis. First, type of cessation aid used continued to show significance. Those that used non-nicotine prescription aids were $88.9 \%$ successful, compared to $28.6 \%$ that used nicotine replacement products and $20 \%$ that used no pharmacotherapy ( $p=0.014$, Table 2). Setting a quit date also continued to be a predictor of smoking cessation, with $80 \%$ of those setting a quit date being successful compared to $27.3 \%$ of those not setting a quit date $(p=0.016$, Figure 1). Additionally, number of clinic sessions attended became a marker of success in this group as those that attended more clinic sessions were more successful (4.82; $\mathrm{SD}=1.5$ verses $3.1 ; \mathrm{SD}=1.7$ sessions; $p=0.026$ ). Finally, type of insurance appeared to be a factor in successfulness, as $76.9 \%$ of patients with private insurance were successful compared to $16.7 \%$ in state-funded programs $(p=0.015)$. All other endpoints did not predict success (Table 3 ).

Perceived Clinic Value. Patients that quit smoking rated their cessation therapy with higher satisfaction than those that did not quit smoking $(8.56 \pm 0.88$ verses 6.71; $S D=2.81, p=0.139$ ). Additionally, group interaction was with equal with a discussion about medications for the highest amount of satisfaction in the clinic (4.53; $S D=0.77)$, followed by steps to prepare you to quit smoking $(4.42 ; \mathrm{SD}=0.69)$, and withdrawal effects of nicotine (4.32; $\mathrm{SD}=0.89$, Table 4). 


\begin{tabular}{|l|c|}
\hline Table 4: Rating of Session Topics \\
\hline Topic & $\begin{array}{c}\text { Rating } \\
\text { Mean (SD) }\end{array}$ \\
\hline Group Interaction & $4.53(0.77)$ \\
\hline Medications to help you quit & $4.53(0.77)$ \\
\hline Steps to prepare you to quit & $4.42(0.70)$ \\
\hline Withdrawal effects of nicotine & $4.32(0.89)$ \\
\hline Discussions about other's quit attempts & $4.21(0.86)$ \\
\hline Risks of Smoking/Benefits of Quitting & $4.05(1.08)$ \\
\hline Exercise & $3.74(0.93)$ \\
\hline Former smoker guest speaker & $3.58(0.84)$ \\
\hline Weight gain & $3.58(0.96)$ \\
\hline Log of cigarettes & $3.11(0.99)$ \\
\hline Brand switch & $2.74(0.93)$ \\
\hline $\begin{array}{l}\text { \#Patients were asked to rate session topics on a Likert } \\
\text { scale from 1 to 5 with 1 being not helpful and 5 being very } \\
\text { helpful. }\end{array}$ \\
\hline
\end{tabular}

\section{DISCUSSION}

The pharmacist-managed Smoking Cessation Group Clinic successfully aided approximately half its participants quit smoking at 3 and 6 months. Other smoking cessation group programs found similar results, including $42 \%$ and $26 \%$ at 3 and 6 months respectively ${ }^{10}$ and $28 \%$ at 6 months. ${ }^{11}$ This study is also the first one to look at predictors of cessation within a pharmacist-managed group clinic. Even though patient enrollment was low, significant factors predicting success were seen.

Having more previous quit attempts was associated with being more likely to quit smoking at both 3 and 6 months. A study published in 1997 showed similar results. This cohort study, which randomly selected over 13,000 smokers in the United States and Canada showed that those subjects that had 2 or more quit attempts were more likely to stay smoking-free. ${ }^{13}$ The result of our analysis implies that having more previous quit attempts is not only a predictor of success, but is also sustainable over a longer period of time. One theory behind this success is that people with more quit attempts have experience and therefore know what situations to avoid and what behavioral and cognitive changes to make. This information was limited as previous quit attempts were patient reported, thus could have been over- or underestimated.

Additionally, using the non-nicotine prescription cessation aids of varenicline and bupropion were associated with a higher cessation rate than nonprescription nicotine replacement therapy and no pharmacotherapy combined at both 3 and 6 month data endpoints. One explanation for this is prescription medications could be associated with a higher ease of use than nicotine replacement products. In addition, varenicline became available approximately eight months prior to the first clinic session, and many patients felt that this product would help them be the most successful. Also, because of the expense of this medication and exclusion from the state formulary, it limited use to mostly those with private insurance. This could be the reason why there was a significant rate of success in those with private insurance compared to those in a state funded program.
The Department of Health and Human Services Public Health Guidelines for Treating Tobacco Dependence published two separate meta-analyses within their guidelines that show as the number of minutes spent counseling patients on smoking cessation increase, or as the number of sessions spent with a patient increase, cessation rates also increase. The first meta-analysis, ( $n=35$ studies) compared the number of minutes spent counseling. At $31-90$ minutes the cessation rate was $26.5 \%$ (OR $3.0 ; \mathrm{Cl} 2.3-3.8)$, whereas for 91-300 minutes, the cessation rate was $28.4 \%$ (OR $3.2 ; \mathrm{Cl} 2.3-4.6){ }^{7}$ In the second meta-analysis, $(n=46$ studies $)$ the number of counseling sessions was compared. The cessation rates for $0-1,2-3,4-8$, and $>8$ sessions were $12.4 \%$ (OR 1.0), 16.3\% (OR 1.4; Cl 1.1-1.7), $20.9 \%$ (OR 1.9; Cl 1.6-2.2), and 24.7\% (OR 2.3; Cl 2.1-3.0), respectively. ${ }^{7}$ This correlated with the findings of this study, as there was a significant increase in cessation rates in those that attended three or more (approximately 135 to 270 minutes) compared to one or two sessions (approximately 45 to 90 minutes) at the six month end point.

There were a large number of patients that signed up for the clinic but did not enroll into the clinic. The reason for this can largely be found in the design of the clinic itself. First, the clinic was designed so that each session occurred over the noon hour on Tuesday, with the exception of one clinic group that met in the evening. This was done in order to comply with the schedules of those administering the clinic. This time may not have been ideal for those patients that had to work during the day. Also, we had six, 45 minute sessions which may have been too many sessions for a patient to travel to the hospital. Each clinic period also extended over the course of 8 weeks, which is a large time commitment, and may have led to decreased patient participation over time. Other things that could have factored into attendance rates include weather, difficulty traveling to the hospital and perceived value of the clinic itself. As there was no charge for participation in the clinic, patients may have had a decreased vested interest in the clinic.

Although higher attendance rates increase cessation rates, steps could be taken in order to effectively maximize the pharmacist's time and minimize patient commitment, while also achieving the best patient outcomes in the clinic. Potential adjustments to the clinic design which may improve patient participation include decreasing the number of sessions, lengthening the time spent in each session, meeting at a different time of day, meeting in a location more central to patients, holding patient specific groups (i.e. an employee-only group), and charging a fee for the class to increase the value associated with the clinic. Additionally, the clinic's format was designed so that it would slowly get participants accustomed to not having weekly counseling support. However, as two patients resumed smoking in the time between the end of their clinic and the follow up period, one additional phone call approximately two weeks after the end of the clinic may help increase cessation rates of all patients. Although a significant amount of time was spent advertising the clinic to physicians and 
pharmacists, more time could be spent advertising the clinic to patients as self-referrals were the ones most likely to enroll in the clinic.

Patients that quit smoking rated their smoking cessation aid with higher satisfaction than those that were not smoke free. This has been shown in a previous publication. ${ }^{14}$ It should be noted that those patients that were not smoke free still reported a positive satisfaction with their smoking cessation aid. This indicates that most smokers realize that it is not necessarily the cessation aid that makes the quit attempt a failure, but rather it is the self motivation in cessation that is the major contributing factor to failure. Thus, repeating cessation aids at future quit attempts is still a viable option.

A significant result of this study was that the group design of the clinic was associated with high satisfaction. This is attributed to the idea that most people tend to smoke in groups, therefore quitting in groups will aid in the social aspect of the habit. From observation, it was noted that many participants had a high interest in how others in the clinic were doing on their smoking status. A drawback of a group-style clinic is that some people are not always comfortable in this setting, do not participate, and may feel ashamed in front of the other members if they are not successful.

A major limitation in this study was that smoking status during follow-up was self-reported and attained via telephone. It would be very easy for a patient to misrepresent their smoking status by this method. Chemically verifying abstinence was considered but ruled out due to cost and the short half life of nicotine and cotinine. Another limitation was the small sample size. There was limited participation from inpatient care teams in patient referral. All patients interested in quitting upon admission are counseled regarding smoking cessation prior to discharge; however this did not prove to be a successful avenue of referrals into the clinic. Studies have shown that patients who receive smoking cessation counseling while inpatient and then continue to receive that counseling as an outpatient are most likely to quit smoking after hospitalization, compared to those who do not receive outpatient counseling. ${ }^{7}$ With more inpatient pharmacist participation, the number of enrolled patients into the clinic and successful cessation attempts could increase.

\section{CONCLUSIONS}

The University of lowa Hospitals and Clinics established a pharmacist-managed Smoking Cessation Group Clinic based on its combination of pharmacological and behavioral interventions and group-based, multi-meeting format. As approximately half of participants were successful in quitting at 3 and 6 months, this study further supports the utilization of a clinical pharmacist within a group smoking cessation setting. The group format of the clinic was associated with high satisfaction among clinic participants. More previous quit attempts and type of cessation aid used were predictors of cessation success at 3 and 6 months in this clinic. In the future, the clinic could be tailored to effectively maximize the pharmacist's time, while also achieving the best patient outcomes.

\section{CONFLICT OF INTEREST}

The authors declare no grant support or conflicts of interest. There were no outside funding sources for this project.

\section{References}

1. United States Department of Health and Human Services. Health Consequences of Smoking. Executive Summary. May 27, 2004.

2. American Cancer Society. Cancer Facts and Figures 2006. http://www.cancer.org/downloads/STT/CAFF2006PWSecured.pdf (accessed on March 10, 2009).

3. United States Department of Health and Human Services. Healthy People 2010. Vol. 2. November 2000.

4. Centers for Disease Control and Prevention. Cigarette Smoking Among Adults-United States, 2007. MMWR. 2008;57(44);1221-1226.

5. Centers for Disease Control. Cigarette smoking among adults-United States, 2004. MMWR. 54(44);1121-1124.

6. Fichtenberg CM, Glantz SA. Effect of a smoke-free workplace on smoking behaviour: systematic review. BMJ. 2002:325;188-195.

7. Fiore MC, Jaén CR, Baker TB, Bailey WC, Benowitz NL, Curry SJ, Dorfman SF, Froelicher ES, Goldstein MG, Healton CG, Henderson PN, Heyman RB, Koh HK, Kottke TE, Lando HA, Mecklenburg RE, Mermelstein RJ, Mullen PD, Orleans CT, Robinson L, Sitzer ML, Tommasello AC, Villejo L, and Wewers ME. Treating Tobacco Use and Dependence: 2008 Update. Clinical Practice Guideline. Rockville, MD: U.S. Department of Health and Human Services. Public Health Service. May 2008.

8. Dent LA, Scott JG, Lewis E. Pharmacist-managed tobacco cessation program in veteran's health administration community-based outpatient clinic. J Am Pharm Assoc. 2004;44(6):700-715.

9. Hudmon KS, Berger BA. Pharmacy applications of a transtheoretical model in smoking cessation. Am J Health-Sys Pharm. 1995;52:282-287.

10. Zillich AJ, Ryan M, Adams A, Yeager B, Farris KB. Effectiveness of a pharmacist-based smoking-cessation program and its impact on quality of life. Pharmacotherapy. 2002:22(6),759-765.

11. Dent LA, Harris KJ, Noonan CW. Randomized trial assessing the effectiveness of a pharmacist-delivered program for smoking cessation. Ann Pharmacother. 2009;43:194-201.

12. Fagerstrom KO, Schneider NG. Measuring nicotine dependence: a review of the Fagerstrom Tolerance Questionnaire. J Behav Med. 1989;12(2):159-182. 
13. Hymowitz N, Cummings KM, Hyland A, Lynn WR, Pechacek TF, Hartwell TD. Predictors of smoking cessation in a cohort of adult smokers followed for five years. Tob Control. 1997;6:s55-s61.

14. Hertel AW, Finch EA, Kelly KM, King C, Lando H, Linde JA, Jeffrey RW, Rothman AJ. The impact of expectations and satisfaction on the initiation and maintenance of smoking cessation: an experimental test. Health Psychol. 2008;27:s197-s206. 